\title{
Characterization of Gum Arabic As Viscosity Modifying Agent (VMA) for Producing Self-Compacting Concrete (SCC)
}

\author{
Yousif Hummaida Ahmed ${ }^{1,2,}$, Moaz Ibrahim Rahamtalla ${ }^{2}$ and Khalid Salah Eldin ${ }^{1}$ \\ 1 Department of Civil Engineering, Faculty of Engineering, University Of Khartoum, Sudan \\ 2 Civil Engineering Department, Red Sea University, Omdurman, Sudan \\ * Corresponding author: Yousif Hummaida Ahmed (e-mail: y.hummaida@uofk.edu). \\ Article history: Received 14 March 2020, Received in revised form 4 November 2020, Accepted 11 November 2020
}

\begin{abstract}
This study aims at finding alternative indigenous Sudanese material for concrete admixtures that are necessary for casting concrete in hot weather of the Sudan. The objective of this study to classify Gum Arabic (GA) namely, Acacia Senegal (known locally as Hashab Gum) as viscosity modifying admixture (VMA) for lowering powder content in self compacting concrete (SCC). The methodology of the study is based on the European standards BS EN 934-2 \& BS EN 480-15 that are used as a paradigm to classify GA as the VMA. Three trial SCC test mixes containing different quantity of cement, namely $(400,370$ and 350$) \mathrm{Kg} / \mathrm{m}^{3}$ as powder content. A dose of GA $0.2 \%$ by weight of cement is applied after being dissolved in water at a concentration of $30 \%$ by water weight. The water/cement ratio $(\mathrm{W} / \mathrm{C})$ is kept constant as 0.45 for all mixes. The results of this study showed that the $0.2 \%$ GA dosage is appropriate and satisfied all criteria set by BS EN 934-2: 2009 for VMA. Using 0.2\% GA as VMA lower the powder of SCC from $400 \mathrm{~kg}$ to $350 \mathrm{~kg} / \mathrm{m}^{3}$ while maintaining the SCC fresh properties.
\end{abstract}

Keywords: Gum Arabic, Viscosity Modifying Agent, SCC.

\section{INTRODUCTION}

According to BS EN 206-9:2010 [1]. Self Compacting Concrete (SCC) is defined as "Concrete that is able to flow and compact under its own weight, does not require vibration for placing, without segregation or bleeding[2], fill the formwork with its reinforcement, ducts, boxouts etc., whilst maintaining homogeneity". The SCC may be classified into three types: the powder type, VMA type and the blend of the two types [3].

- The powder type SCC is characterized by the large amounts of powder (all material with size $<0.125 \mathrm{~mm}$ ) which is usually in the range of (550 to $650 \mathrm{~kg} / \mathrm{m}^{3}$ ).

- In the VMA type SCC, the powder content may be lower (350 to $450 \mathrm{~kg} / \mathrm{m}^{3}$ ) .The segregation resistance is mainly controlled by a
VMA and the yield point by the addition of superplasticizer.

- In the combination type of SCC, the powder content is between (450 to $550 \mathrm{~kg} / \mathrm{m}^{3}$ ) but in addition, the rheology is also controlled by a VMA as well as an appropriate dosage of the superplasticizer.

The powder type of SCC requires high cement content. This leads to increase in cost and will be problematic if used in the tropical weather of the Sudan by increasing risk of thermal cracks and delayed ettringite formation in deep section, hence reduces durability of concrete.

Adding VMA for SCC to improve the stability to allow for variations during construction, as SCC is very sensitive to vaiation of ingredients properties, and increase cohesion and segregation resistance[4]. Most VMA's are supplied as dispersed in a liquid to make dosing easier and improve dosing accuracy. The dosage depends on 
the application but typically ranges from $\mathbf{0 . 1}$ to1.5\% by weight of cement but can be varied for specific applications [3]. Sudan imports all its chemical admixtures from abroad and this drains hard currency which is very scarce. The use of imported admixtures is costly also manufactured admixtures have short shelf-life and require special storage conditions (normally 12 months) [5].

Raw GA can be used as a viable alternative as it does not have an expiry date and is indigenously cultivated in the Sudan. Natural gums are described as Viscosity Enhancing Admixtures (VEAs) and anti-washout admixtures that are water-soluble polymers that increase cohesion and stability of cement-based materials [6].

This paper is the first up to our knowledge to use the BS EN 480[15] and BS EN934-2 [7] codes and specification to classify GA as VMA.

The aim of this study is to classify GA namely, Acacia Senegal (known locally as Hashab) as VMA, and then lower the quantity of powder used in SCC production. The approach to achieving this study is summarized as follows:

- Collection of samples of GA (Acacia Senegal known locally as Hashab) from local sources.

- Classification of the GA as VMA according to BS EN 934-2 [7] requirements following methods listed in BS EN 480 [15] , concrete reference will be used and designed using the empirical design method that is based on data and limits values stated in EFNARC [3].

- Preparation of mixes containing GA as VMA with the same dosage $0.2 \%$ of cement weight based on levels and lowering powder contents reported in [8-12].

- Conducting testing and check conformity according to BS EN BS EN 934 [6] and interpreting results of fresh and hard properties of self-compacting concrete. This paper consists of four sections: Introduction (Section1), materails and Methods (Section 2), Results and Discussion (Section3) and Conclusions and Recommendation (Section 5).

\section{MATERIALS AND METHODS}

\section{A. Raw Materials Testing}

Sakhr Al-Sudan cement is used in the mix which is a locally OPC produced by Al-Takamol company. OPC cement class $42.5 \mathrm{~N}$ conforming to
BS EN 197-1. The specific gravity of the cement was measured. Uncrushed coarse aggregate conforming to $14 \mathrm{~mm}$ graded sized of BS-EN8821992 \& natural sand conforming to BS5075-1:1982 for fine aggregate, the specific gravity of the coarse and fine aggregate was measured 2.65, 2.63 respectively. Water and GA (Hashab type) were used. High range water reducing YaraconSP650 conforms with BS 5075, BS: EN 934-2, ASTM C494 Type $\mathrm{F}$ and relative density of SP was 1.15 at $25^{\circ} \mathrm{C}$. All raw materials were tested in accordance with requirement of BS EN 480-1:2900, except the aggregates which were tested in accordance with requirements of BS 480-15 Table 1. The OPC has initial \&final setting time of 157 \&196 minutes respectively and compressive strength of $45 \mathrm{~N} / \mathrm{mm} 2$ at 28 days. The tests carried out on coarse and fine aggregates for concrete mixes by using procedures conforming to the correspondent parts of BS EN1097[13]\& BS EN 933-1[14] included: particle density, water absorption, moisture content and sieve analysis. The tests were carried out on the sand by using procedures conforming to the correspondent parts of BS 1097included: water absorption and moisture content.

\section{B. Mix Proportions}

There are many mix design methods of SCC. The best estimation of SCC proportion was based on trial mixes to fulfil requirent of Table 2 in BS EN 480 [15] and adjustment of initial mixture. European guideline [4] determined indication of the typical range of constituents in SCC by weight and volume. According to BS EN 480 [15] requirements, concrete reference was used and designed using Empirical method as shown in Table 1. Three trial test mixes containing different quantity of cement, namely $(400,370$ \& 350 $\mathrm{kg} / \mathrm{m}^{3}$ ). A dose of GA $0.2 \%$ by weight of cement was carried out after being dissolved in water. This dosage was based on dosages reported by J.J in [8]. The water/cement ratio 0.45 for all mixes, the water content of the test mixes varied between same amount as reference mix and reduced amounts in order to achieve equal consistence. The amounts of cement reduction in mix3-370 $\mathrm{kg}$ and mix4-350 $\mathrm{kg}$ were replaced by $\mathrm{CA}$ and FA while maintaining the proportion ratio of $\mathrm{CA}$ : $\mathrm{FA}$ in control mix. 
TABLE1: MIX PROPORTIONS OF SCC ACCORDING TO EMPIRICAL DESIGN METHOD

\begin{tabular}{c|c|c|c|c|c|c|c}
\hline \hline Mix & $\begin{array}{c}\text { CA } \\
\mathrm{kg} / \mathrm{m} 3\end{array}$ & $\begin{array}{c}\mathrm{FA} \\
\mathrm{kg} / \mathrm{m} 3\end{array}$ & $\begin{array}{c}\text { Cement } \\
\mathrm{kg} / \mathrm{m} 3\end{array}$ & $\begin{array}{c}\text { Water } \\
\mathrm{kg} / \mathrm{m} 3\end{array}$ & W/C & $\begin{array}{c}\text { SP } \\
\mathrm{kg} / \mathrm{m} 3\end{array}$ & GA kg/m3 \\
\hline Reference Mix1 & 820 & 1020 & 400 & 180 & 0.45 & 7 & 0.0 \\
\hline Mix2-400 kg/GA & 820 & 1020 & 400 & 180 & 0.45 & 7 & 0.8 \\
\hline Mix3-370 kg/GA & 835 & 1038 & 370 & 167 & 0.45 & 7 & 0.74 \\
\hline Mix4-350 kg/GA & 852 & 1060 & 350 & 157 & 0.45 & 7 & 0.7 \\
\hline \hline
\end{tabular}

\section{Test Methods \&Mixing procedure}

The Forced pan mixer was used to make mixes, Unlike the mixing procedure stated in BS EN 480[15], the mixing began by dry mixing of sand with powder for about 2 minute. Two-thirds of the total water content was slowly poured while the mixer was running. Then CA was added with the remaining third of water, then third of SP was added and mixed for 2 minutes. Finally BS EN 480[15], two third of SP and GA solution was slowly poured and mixed for extra 7 minutes [16]. Tests carried out on the reference concrete was performed as comparative tests and compared to Table 13 of BS EN 934-2:2009 requirements [7].

In this study, according to BS EN 206-9:2010 [1] and BS EN 12350-8 [17] the following tests were used, slump flow test, and sieve segregation to measure and classification the fresh properties of SCC. Moreover, compressive strength was measured (28days) according to BS EN 12390-3:2000[18] using cubes $\left(150^{*} 150^{*} 150\right) \mathrm{mm}$ cast without compaction.

\section{RESULTS AND DISCUSSION}

This section presents the results obtained from the testing program and discusses the effect of GA in SCC concrete mix and knowing the extent to which the powder can be reduced while maintaining the properties of the SCC when using GA as VMA. Also, it includes comparison between these results and specific requirements according of BS EN 934-2:2009 to classify the GA as VMA. The results were obtained from the slump flow test, T500 test, air content and compressive strength test. Three different quantity of cement with $0.2 \%$ of GA were tested $\left(400,370 \& 350 \mathrm{~kg} / \mathrm{m}^{3}\right)$. The result obtained by conducting the test methods on the fresh mixes and hardened concrete.

\section{A. Influence of GA addition on Slump Flow (SF)}

Fig.1 shows the slump flow spread obtained from slump flow testing of SCC)

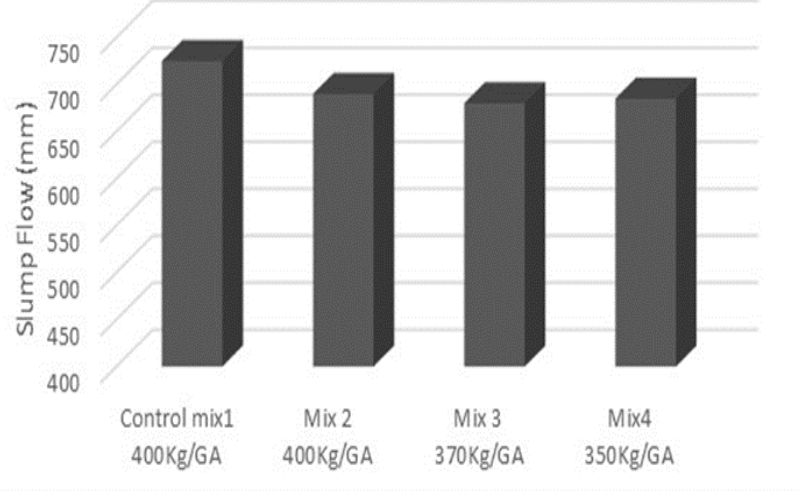

Fig 1: Slump Flow of different Mix (mm)

Fig 1 shows that the Control Mix 1 and test Mix2 with addition of GA by $0.2 \%$ by weight of cement decreases the slump flow However, when the quantity of cement was reduced in the presence of GA as in test mixes Mix3 and Mix4 until $(370,350 \mathrm{~kg} / \mathrm{m} 3)$ respectively, it was found that the slump flow increased by a small amount and satisfied requirements and specification in BS EN 206-9-2010[1]. This indicates that there is no remarkable effect on slump flow when the cement was reduced to the above quantity.

B. Influence of GA addition on viscosity (flow rate Test, T500 time)

Fig. 2 shows the T500 obtained from slump flow testing of SCC) Mix2, Mix3 and Mix4 containing $0.2 \%$ of GA had higher spread time (T500)compared to Control Mix1, which is due to extensive cohesion and viscosity exihibted by these mixes. 


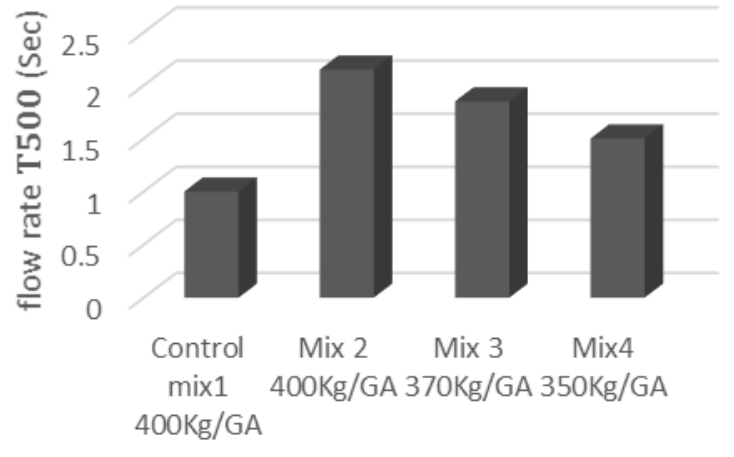

Fig 2: flow rateT500 of mixes

That makes the paste slow and limit the viscosity noticeably which means increasing of filling time ability. This agrees with [20] who observed the addition of GA increased the T500, i.e. decreased the rate of flow. This means the GA is enhancing the viscosity and acts as VMA.

This decrease in the flow rate (or increase in viscosity) is due to the GA having a high-molecular-weight polysaccharide composed of one or a few different mono-saccharide repeating units joined together by glucosidal bonds. The multiple hydroxyl groups in the structure of these molecules allow hydrogen bonding between GA molecules, a mechanism that is responsible for building viscosity in solution [20].

\section{Influence of GA addition on Air Content}

Fig 3 shows the air content of the control mix and the three test mixes containing $0.2 \%$ dosage of GA. The air content value of the control concrete Mix 1 as $1 \%$ by volume of concrete. The air content

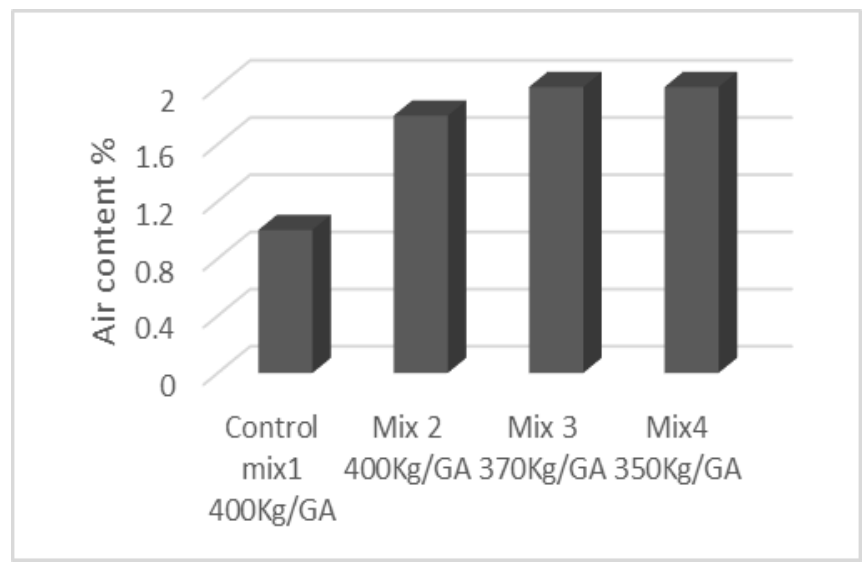

Fig 3: Air content of mixes

of Mix 2 was $1.8 \%$ and for Mix 3 \& Mix 4 was $2 \%$ higher than the control mix .It can be concluded that GA increased the air content. This agrees with the comment of Ramachandran [19] about pumping aids admixtures containing natural gums. These admixtures have inherent surfactant properties that lower the surface tension of the aqueous phase of the mix. Consequently, dosages above optimum levels will entrain unjustified air. It is worth noting that during preparing the GA admixture (by dissolving in mixing water) air bubbles were observed. Li et al (2009) [21] had been reported that the air bubbles formed in concentrated aqueous GA solutions (30\%) seem to also have a significant effect on the rheological behavior especially in the low shear rate range. It could indicate that besides VMA, GA could be used as air-entraining admixture; however, further investigation is required in this aspect.

\section{Influence of GA addition on segregated portion} $(S R)$

It is noted from Fig 4 that adding GA by $0.2 \%$ of the cement weight to SCC reduced the segregated portion percent (SR) when comparing control Mix1with test Mix2. This means that adding GA increases and enhances the resistance of the SCC to bleeding, segregation and surface settlement.

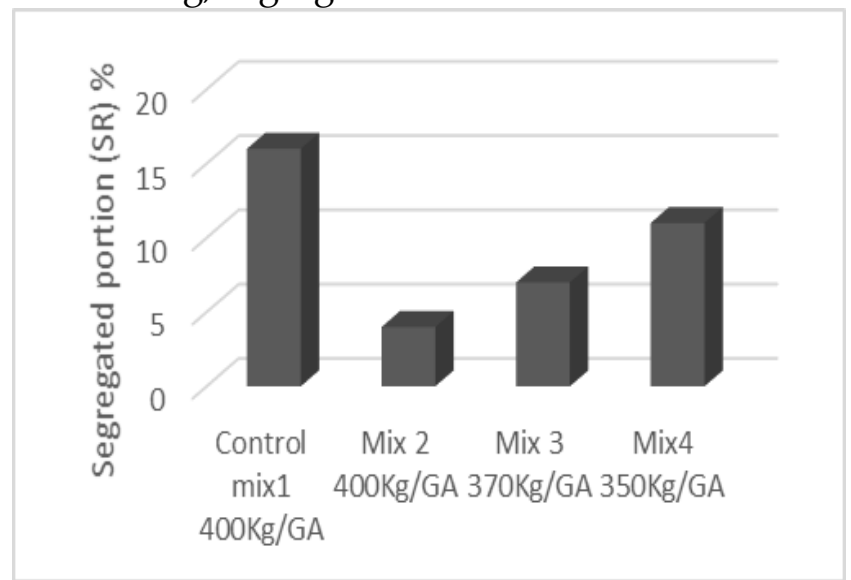

Fig 4: Segregated portion of mixes (SR)

Although all of the above mixes are stable and resistant to bleeding, it is observed in Mix3 and Mix4, i.e. with decrease in powder with the presence of GA reduces the resistance of SCC to segregation compared to Mix2, but still lower than the control Mix1without GA and having higher powder content. This agrees with comment of Khayat [20] about the effect of VMA on stability of SCC who attributed this stability is due to the incorporation of GA molecules. He mentioned that the GA can adsorb some of the 
free water in the system, thus reducing bleeding and surface settlement. The enhanced yield stress and plastic viscosity, as well as the structural build-up of the static yield stress with rest due to the addition of VMA. The VMA can improve the capacity of the liquid phase to suspend solid particles and decrease the rate of sedimentation (Stokes' law) [20].

\section{E. Influence of GA addition on Compressive Strength}

Fig 5 show that at equal W/C ratio with water reduction, adding $0.2 \%$ dosage of GA produced lower strength than the control mix, indicating that GA acts as strength retarder (i.e. hardening retarder).

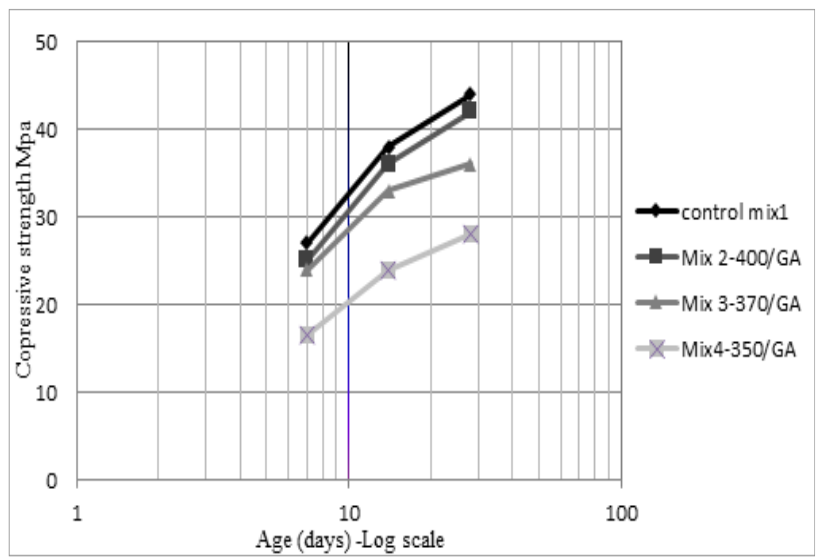

Fig5: Compressive strength of mixes

It is most likely that the retardation effect of GA for the strength is attributed to the actions of its sugars and glucuronic acids ingredients [21]. Figure 4-5 agrees with Mail vaganam [22] and ref [23] observations. The reduction of compressive strength with lowering the powder content albiet mainiting the same $\mathrm{W} / \mathrm{C}$ ratio may be attributed to the decrease in cement/aggregate ratio.

\section{F. Classification of $0.2 \%$ GA as VMA admixture}

The results of SCC tests on control and $0.2 \%$ GA mixes at equal consistence were interpreted in accordance with Table 13 of BS EN 934-2:2009 requirements of admixtures. These interpretations are shown in Table2.

\section{CONCLUSIONS}

From the tests results obtained it can be concluded that:

- At $0.2 \%$ GA dosage, satisfied all criteria set by BS EN 934-2: 2009 for viscosity modifying admixture (VMA).
- Using $0.2 \%$ GA as VMA can tolerate lowering the powder of SCC from 400 to $350 \mathrm{~kg} / \mathrm{m}^{3}$ while maintaining the fresh properties that characterized SCC.

- Adding GA increases air content and decreases compressive strength of SCC that means the GA acts as strength retarder.

- Adding GA enhances the stability and resistant segregation of the SCC.

\section{RECOMMENDATIONS}

For future studies the following is recommended:

- Classification of other types of natural GA as VMA, such as Acacia Seyal ( known locally as Taleh), guar gum and gum of Acacia Nileatoica .

- Further study should focus on preparation of GA solution to be used as admixture; this may need an optimization for chemical stabilization and storage environment.

- Further work in this field must be carried out using other types of super plasticizer and raw materials.

- The increase in viscosity when using GA hinders the sieve segregation test, so recommend using a column segregation test according to ACI 237R-07[24] measure stability.

\section{REFERENCES:}

[1] British Standard Institution (BSI) 2010, Additional Rules for Self-Compacting Concrete (SCC)," Br. Stand. Publ.,BSI,BS EN 206-9.

[2] C. Shi, Z. Wu, K. Lv, and L. Wu, "A review on mixture design methods for self-compacting concrete," Constr. Build. Mater., vol. 84, pp. 387-398, 2015.

[3] E. The, E. Federation, and C. A. Associations, "Guidelines for Viscosity Modifying Admixtures For Concrete," no. September, 2006.

[4] S.-C. C. E. P. Group, The European guidelines for self-compacting concrete: Specification, production and use. International Bureau for Precast Concrete (BIBM), 2005.

[5] M. E. Ballal, E. A. El Siddig, M. A. Elfadl, and O. Luukkanen, "Gum arabic yield in differently managed Acacia senegal stands in western Sudan," Agrofor. Syst. vol. 63, no. 3, pp. 237-245, 2005.

[6] M. a. Montenegro, M. L. Boiero, L. Valle, and C. D. Borsarelli, "Gum Arabic: More Than an Edible Emulsifier," Prod. Appl. Biopolym., vol. 17, no. 3, p. 220, 2012.

[7] British Standard Institution (BSI) 2009, Admixtures Concr. mortar grout. Concr. admixtures. Defin. Requir. Conform. marking Label., London: BSI,BS 934-2 .

[8] J. Jin, "Properties of mortar for self-compacting concrete." University of London, 2002. 
TABLE 2: PERCENTAGE OF TEST MIXES: CONTROL MIX RESULTS \& CLASSIFICATION STATUS OF $0.2 \%$ GA AS VMA ADMIXTURE.

\begin{tabular}{|c|c|c|c|c|c|c|}
\hline \multirow[b]{2}{*}{ Property } & \multirow{2}{*}{$\begin{array}{l}\text { BSEN934-2:2009 } \\
\text { Requirements }\end{array}$} & \multicolumn{2}{|c|}{ Control mix1 } & \multicolumn{2}{|c|}{ Testmix2GA=0.2 } & \multirow{2}{*}{ Note } \\
\hline & & Value & Percentage & Value & Percentage & \\
\hline Segregated portion (SR) & $\begin{array}{c}\text { Control mix } \geq 15 \% \\
\text { and } \mathrm{SR} \leq 30 \% \text { Test } \\
\text { mix } \mathrm{SR} \leq 70 \% \text { of the } \\
\text { value obtained with } \\
\text { the control mix }\end{array}$ & 16 & $100 \%$ & 4 & $25 \%$ & $\begin{array}{c}25 \%<70 \% \\
\text { OK }\end{array}$ \\
\hline Compressive strength & $\begin{array}{l}\text { At } 28 \text { days: test mix } \geq \\
80 \% \text { of control mix }\end{array}$ & 44 & $100 \%$ & 41 & $93 \%$ & $\begin{array}{c}93 \%>80 \% \\
\text { OK }\end{array}$ \\
\hline Air content $\%$ & $\begin{array}{l}\text { Test mix } \leq 2 \% \text { (by } \\
\text { volume) above } \\
\text { control mix unless } \\
\text { stated otherwise by } \\
\text { the manufacturer }\end{array}$ & 1 & - & 1.8 & $\begin{array}{c}\text { Increase } 8 \% \\
\text { compared with } \\
\text { control Limit }= \\
2+0.8=2.8 \%\end{array}$ & $\begin{array}{c}1.8<2.8 \% \\
\text { OK }\end{array}$ \\
\hline
\end{tabular}

*OK= fulfilled the requirement

Table 7 shows that $0.2 \%$ GA satisfies all the criteria required for VMA classification.

[9] C. M. Athman, "Effectiveness Of Gum Arabic As A Superplasticizer In Self-Compacting Concrete." Jkuat-Pausti, 2018.

[10] B. O. Elah and P. Omeinijie, "The use of gum Arabic as an admixture in concrete," Sch. J. Eng. Technol., vol. 3, pp. 282-292, 2015.

[11] N. Zakka, P.W., Job, O.f, \& Anigbogu, “Ecological Self-compacting Concrete using Gum Arabic as a plasticizer," in West Africa Built Environment Research (WABER), 2015, p. 10.

[12] H. A. I. H. Ibrahim, “Using Gum Arabic as Viscosity Modifying Agent with Natural Pozzolana in Producing,". Publised MSc.Research,Structure and Materials Section.Civil.Eng Dept,Faculity of Eng Sudan Universityof Science and Technology, 2016. http://repository.sustech.edu/handle/123456789/15245.

[13] EN1097, T. S. "1, 2002." Tests for mechanical and physical properties of aggregates-Part 1: Determination of the resistance to ware (Micro deval).

[14] British Standard Institution (BSI) 2012, Tests forgeometrical properties of aggregates Part 1: Determination of particle size distribution-sieving method, London: BSI, BS EN 933-1.

[15] British Standard Institution (BSI) 2013,Admixtures for concrete, mortar and grout part 15: Reference concrete and method for testing viscosity modifying admixtures BSI, BS EN480-15.

[16] Y. H. Ahmed And K.S.Babikir "proportioning self compacting concrete in hot weather of sudan utilizing limestone powder" In conference proceedings civil engineering 2018.

[17] British Standard Institution (BSI) 2010, Testing fresh concrete, Part 8: Selfcompacting concrete, Slump-flow test, London, United Kingdom 2010 BSI, BS EN 12350-8

[18] British Standard Institution (BSI) 2002, Testing hardened concrete Part 3: $\quad$ Compressive strength of test specimens, London: BSI, BS EN 12390-3, vol 2.

[19] V. S. Ramachandran, Concrete admixtures handbook: properties, science and technology. William Andrew, 1996. Published in the united state of america by Noyes Publications. 2nd ad.

[20] K. H. Khayat and N. Mikanovic, "Viscosity-enhancing admixtures and the rheology of concrete," in Understanding the rheology of concrete, Elsevier, 2012, pp. 209-228. https://doi.org/10.1533/9780857095282.2.20

[21] X. Li, Y. Fang, S. Al-Assaf, G. O. Phillips, K. ishinari, and H. Zhang, "Rheological study of gum arabic solutions:
Interpretation based on molecular self-association," Food Hydrocoll., vol. 23, no. 8, pp. 2394-2402, 2009.

[22] N. P. Mailvaganam, 1996, Miscellaneous Admixtures, In V. S. Ramachandran (ed.), ConcreteAdmixtures Handbook, 2nd edn, Elsevier Science, pp. 939-1024.

[23] S. A. A. Satti and Y. H. Ahmed, "Use of Gum Arabic (Acacia Seyal) As Concrete Admixture," in Conference Proceedings Civil Engineering 2018, 2018. http://onlinejournals.uofk.edu/index.php/CCE2018/article/viewFi le/2152/2122.

[24] American Concrete Institute (ACI)."self-cosolidating concrete. " ACI 237R-07,2007,P.30.

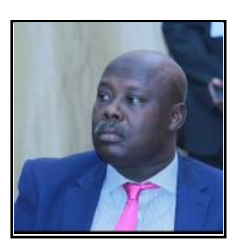

Dr Yousif Hummaida Ahmed (PhD, DIC, BSc), phd in Engineering from emperial college /university of London (1996). Awarded Dr Shawki Saad Scholarship. Specialization concrete durability \&hazardous waste management technologies former Head of Civil engineering Department, faculty of engineering, University of Khartoum, Sudan. Currently Chairman of the governmental Council for Registering and Classifying Engineering Works Contractors.

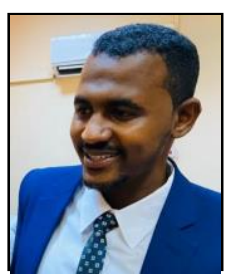

Mr. Moaz Ibrahim ( BSc,MSc).He received a bachelor's degree in civil engineering from Red Sea University and master's degrees in structural engineering from University of Khartoum in sudan.

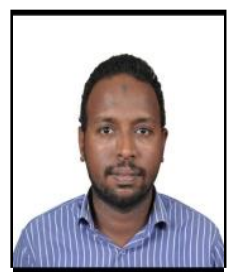

Mr. Khalid Salah (BSc,MSc) is a PhD student at University of Khartoum. he received a bachelor's degree in civil engineering from Omdurman Islamic University and master's degree in structural engineering Khartoum University in Khartoum, Sudan . He is interested in self compacting concrete researches. Currently works for Ouf ready mixed concrete as a concrete technologist 